\title{
Managing Foliar Diseases of Processing Sweet Corn in New York with Strobilurin Fungicides
}

\author{
D. A. Shah and H. R. Dillard, Department of Plant Pathology and Plant-Microbe Biology, Cornell University, New \\ York State Agricultural Experiment Station, Geneva 14456
}

\begin{abstract}
Shah, D. A., and Dillard, H. R. 2010. Managing foliar diseases of processing sweet corn in New York with strobilurin fungicides. Plant Dis. 94:213-220.

Processing sweet corn (Zea mays) growers in New York are more concerned about the cost effectiveness of fungicide use against foliar fungal diseases (common rust and Northern corn leaf blight) and less about whether such sprays will reduce disease intensity. To address this concern, field trials were done in 2006 and 2007 with three processing sweet corn hybrids (Jubilee, Bold, and GH 9597) that differed in susceptibility to common rust and Northern corn leaf blight, and two strobilurin fungicides (azoxystrobin and pyraclostrobin). Single strobilurin applications were applied in response to foliar disease severity thresholds of 1,10 , and $20 \%$. Single fungicide applications did reduce foliar disease severities. Applications were most cost effective when made in response to the 1 and $10 \%$ foliar severity thresholds, and generally only in the susceptible hybrid Bold. Spraying at the $20 \%$ severity threshold did reduce final foliar disease severity but was not cost effective. Azoxystrobin and pyraclostrobin were equally effective in disease management. The results suggest that a single application of a strobilurin fungicide against common rust and Northern corn leaf blight can be cost effective for New York processing sweet corn growers when such an application is made before foliar disease severity exceeds $20 \%$.
\end{abstract}

Processing sweet corn (Zea mays L.) in New York State (NY) is grown on about 7,600 ha annually, with a net farm gate value of US\$8.5 to 9.5 million (National Agricultural Statistics Service). Within NY, the most prevalent foliar disease of processing sweet corn is common rust, caused by Puccinia sorghi Schwein. P. sorghi does not overwinter in NY; common rust infections are initiated anew each year after passive atmospheric transport of live $P$. sorghi urediniospores into NY from elsewhere $(13,27,28)$. Common rust is a concern mainly in late-season processing sweet corn $(3,16)$, because viable urediniospores of $P$. sorghi do not usually arrive into NY until after the first week of July (28). Northern corn leaf blight (NCLB), caused by Exserohilum turcicum (Pass.) K.J. Leonard \& Suggs, occurs less frequently than common rust and is also mainly confined to late-season sweet corn. Like $P$. sorghi urediniospores, conidia of E. turcicum may be dispersed by atmospheric transport. However, unlike $P$. sorghi, E. turcicum is capable of overwintering in NY as mycelia or conidia on

Corresponding author: D. A. Shah

E-mail: das28@cornell.edu

Present address of D. A. Shah: 4662 Vrooman Drive, Lewiston, NY 14092.

Accepted for publication 7 October 2009.

doi:10.1094/PDIS-94-2-0213

(C) 2010 The American Phytopathological Society infected crop residue (8); most E. turcicum inocula originates from debris within the field. Both foliar pathogens reduce sweet corn yields. For every $10 \%$ increase in common rust severity prior to harvest, yield is reduced by 2.4 to $7.0 \%$ in processing sweet corn (29). Similarly, a $10 \%$ increase in foliar severity reduces yield by 4.3 to $10.1 \%$ in the NCLB-susceptible hybrid Jubilee (15), and by 2.3 to $8 \%$ across hybrids in general (20). Yield reductions due to NCLB are potentially greater because this disease is capable of more extensive leaf damage than that caused by common rust pustules, although the individual effects may be difficult to separate when both diseases co-occur $(20,30)$.

Sweet corn foliar diseases are best managed by an integrated approach consisting of timing of planting, hybrid selection, crop debris management, disease scouting, and foliar fungicides (11). For example, fresh-market sweet corn growers in NY avoid common rust epidemics on the highly susceptible hybrid Temptation by planting during early spring, so that ears are almost mature by the time $P$. sorghi urediniospores first begin to arrive. Host resistance is the single, most effective way of managing foliar diseases in sweet corn $(5,8,16,19)$. Nevertheless, pathogen population evolution or shifts can render host resistance less effective than desired (17). Also, market preferences may mean that susceptible or partially resistant hybrids are still grown during the late season when they are more at risk to disease epidemics (19). Fungicides are the last course of ac- tion in managing foliar diseases in sweet corn (11). A range of products are available, but NY processing sweet corn growers are shifting from protectant fungicides (2) to products within the triazole and strobilurin classes. Reasons for the shift are possibly varied but the forces involved may be larger than individual grower choice. For example, in September 2008, United Phosphorus, Inc. submitted a voluntary cancellation of all registrations for maneb, one of which was for use on sweet corn in NY. Coincidentally, a recent study showed that exposure to maneb increases the risk of Parkinson's disease (1). Beyond human health concerns, there is growing interest in assessing the environmental impact of pesticides (33), and some of the older chemistries have more of a negative environmental impact than the strobilurin compounds.

The strobilurin fungicides offer the advantages of a longer spray interval and curative properties in comparison to protectant fungicides $(11,14)$. However, cost and limited time during the growing season restrict processing sweet corn growers in NY to a single fungicide application for foliar disease control. Under these circumstances, NY growers are interested in two basic questions: (i) can a single application of a strobilurin fungicide provide costeffective control of foliar diseases and (ii) when should such an application be made? Here, cost effectiveness is defined as an increase in realized product value (in response to spraying) that, at a minimum, offsets the cost of fungicide application (29). Both of the above questions, including a consideration of cost effectiveness, are components of threshold theory (35). A single application of a strobilurin fungicide can delay foliar disease progress in corn $(6,14,25,30,31)$ but final disease severity, at least for common rust, has to be reduced by at least 12 to $15 \%$ for that application to be cost effective in processing sweet corn (29). Also, the economic return on fungicide use against foliar diseases in sweet corn is moderated by the effects of a hybrid's level of resistance on disease progress (18). Most previous research on applying strobilurins against foliar diseases in sweet corn or other corn focused on multiple applications beginning at disease onset or on combinations with fungicides in other classes, in environments much more favorable for disease development than typically found in NY (22- 
24,26,30,32). These previous studies, representing multiple fungicide applications, combinations of chemistries, and relatively disease-conducive environments, are not generally transferable to the circumstances encountered by NY processing sweet corn growers. The objective of the current study was to investigate the cost effectiveness of single applications of strobilurin fungicides against foliar diseases in processing sweet corn, conditional on the applications being made at given foliar disease severity thresholds.

\section{MATERIALS AND METHODS}

Location, hybrids, fungicides, and treatments. Field trials were completed in a section of a sweet corn production field in Le Roy, NY in 2006 and 2007. Trials were maintained (planting, fertilization, spraying, and harvest) by A.C.D.S. Research, Inc. (North Rose, NY). Three hybrids (Bold, Jubilee, and GH 9597; Rogers Brand Vegetable Seeds, Boise, ID) were used. All three are processing, yellow-su type, and differ in their susceptibilities to $P$. sorghi races and to E. turcicum (Table 1). Two commercial strobilurin fungicide products were used: Quadris (azoxystrobin; Syngenta Crop Protection, Greensboro, NC) and Headline (pyraclostrobin; BASF Corporation, Florham Park, $\mathrm{NJ})$.

Rainfall was recorded on-site between the first and last quantitative foliar disease assessments with a Taylor 2710N Rain Gauge (Taylor Precision Products, Oak Brook, IL) mounted at the soil line. Daily temperature, relative humidity, and leaf wetness duration were obtained from the Batavia weather station of the New York State IPM Network for Environment and Weather Applications. The Batavia station was located $19 \mathrm{~km}$ from the trial site.

Table 1. Reactions of sweet corn hybrids to common rust, Northern corn leaf blight (NCLB), and Stewart's wilt $(\mathrm{Sw})^{\mathrm{a}}$

\begin{tabular}{lccccc}
\hline & \multicolumn{5}{c}{ Reaction $^{\mathbf{b}}$} \\
\cline { 2 - 6 } Hybrid, year $^{\mathbf{c}}$ & avir & G-vir & D-vir & NCLB & Sw \\
\hline Bold & & & & & \\
2004 & $\mathrm{Rp}$ & 9 & 9 & 4 & 1 \\
2005 & $\ldots$ & 0 & $\ldots$ & 4 & 3 \\
2006 & $\mathrm{Rp}$ & $\mathrm{Rp}$ & 9 & 3 & 3 \\
2007 & $\mathrm{Rp}$ & $\mathrm{Rp}$ & 8 & 2 & 2 \\
GH 9597 & & & & & \\
2004 & $\mathrm{Rp}$ & $\mathrm{Rp}$ & $\mathrm{Rp}$ & 5 & 1 \\
Jubilee & & & & & \\
2004 & 6 & 5 & 5 & 7 & 9 \\
2005 & $\ldots$ & 5 & $\ldots$ & 8 & 8 \\
2006 & $\ldots$ & 6 & 6 & 9 & 8 \\
2007 & 7 & 7 & 7 & 9
\end{tabular}

${ }^{a}$ Data are from the annual Sweet Corn Disease Nursery Reports, available online (http://sweetcorn.uiuc.edu/index.html). GH 9597 was not evaluated in 2005 to 2007.

${ }^{\text {b }}$ Hybrids were screened against three Puccinia sorghi isolates: avr = avirulent to $R p 1 D$ or $R p 1 G$; Gvir $=$ virulent to $R p 1 G$; D-vir = virulent to $R p 1 D$. Hybrid reactions are shown to common rust isolates, races 0 and 1 of Northern corn leaf blight, and Stewart's wilt. $\mathrm{Rp}=$ resistance response reaction because the hybrid has Rp resistance to the specific $P$. sorghi isolate. Otherwise, reactions were rated on a 1-to-9 scale, where $1=$ resistant, $3=$ moderately resistant, $5=$ moderate, $7=$ moderately susceptible, and $9=$ susceptible.

c Year evaluated. verity ratings were done by the first author. Rust severity was assessed on each nonsenesced, unfurled (collar visible), or $>75 \%$ unfurled leaf on each of 3 to 10 plants per plot. Severity per leaf was assessed on a 0 to $100 \%$ scale following Peterson et al. (21). The data were summarized after each rating date to produce an estimate of the mean severity per plant for each plot. This enabled spray decisions based on crossed severity thresholds to be relayed to A.C.D.S. personnel within a day of disease assessments.

Plots scheduled for biweekly fungicide applications were sprayed on 27 July, 10 August, 24 August, and 7 September 2006. For all other plots, sprays were applied if the respective disease severity threshold had been exceeded. All fungicide applications were made with a $\mathrm{CO}_{2}$ backpack sprayer, 3.1-m-swath handheld boom, 281 liters ha ${ }^{-1}, 275.8 \mathrm{kPa}, 3.1 \mathrm{~km} \mathrm{~h}^{-1}$. Headline and Quadris were applied at $168 \mathrm{~g}$ a.i. ha $\mathrm{h}^{-1}$ (672 $\mathrm{ml}$ of product per hectare). For each application, one pass of the sprayer was made through the plots.

Bold and Jubilee plots were harvested on 27 September 2006 (90 days after planting [dap]), and the GH 9597 plots were harvested on 10 October 2006 (103 dap). The two center rows of each plot were harvested, ears were husked and weighed, and the mean weight per ear was calculated for each plot.

2007 Trial. The experimental layout was the same as in 2006, except there were three blocks instead of four. Data collection was very time-consuming in 2006 and, because all ratings were done by the first author only, the rationale was that reducing the design to three blocks would enable more temporal ratings per plot. Plots were sown on 25 June 2007. Plot dimensions and interplot distances were as in 2006 but each plot was $3.66 \mathrm{~m}$ long. Stand counts were assessed on 24 and 25 July 2007.

The entire trial was surrounded by four border rows, sown on 15 June 2007, consisting of a mixture of the hybrids Bold and Jubilee. During dusk on 19 July 2007, the borders were inoculated with a suspension of $P$. sorghi urediniospores collected earlier in the day from a planting of the hybrid Temptation, on which there were open pustules, near Lockport, NY. The inoculations were repeated on 26 July 2007 following the same procedure. The inoculated borders were to serve as a localized source of $P$. sorghi urediniospores in the hope of increasing disease severity beyond that observed in 2006. The main trial was not inoculated. Common rust pustules were first observed on a few plants in the main trial on 21 July 2007.

G-Max Lite 5L (atrazine; BASF Corporation) was applied at 3.5 liters $\mathrm{ha}^{-1}$ on 29 June 2007 for weed control. Accent 75DF (nicosulfuron; DuPont Crop Protection, Wilmington, DE) was applied at $47 \mathrm{~g} \mathrm{ha}^{-1}$ 
on 17 July 2007 for quackgrass (Elymus repens (L.) Gould subsp. repens) control. Baythroid 2EC ( $\beta$-cyfluthrin; Bayer CropScience, Research Triangle Park, NC) was applied at $212 \mathrm{ml} \mathrm{ha}^{-1}$ on 17 July 2007 for corn flea beetle control. Warrior 1CS (281 $\mathrm{ml} \mathrm{ha}{ }^{-1}$ ) was applied for corn earworm (Helicoverpa zea Boddie) control on 4 and 13 September 2007.

Fungicide spray timings were the same as in 2006 (unsprayed or sprayed at 1, 10, or $20 \%$ foliar disease severity thresholds, hereafter simply referred to as thresholds). The biweekly spray treatments used in 2006 were replaced by a spray at first detection of common rust (applied on 23 July 2007). A miscommunication led to those same plots being sprayed a second time on 4 September 2007. Fungicides were applied as described above for 2006 but at 234 liters ha ${ }^{-1}$.

NCLB was first observed in the borders on 25 July 2007 and eventually moved into the main trial. Initially, common rust and NCLB severities were assessed separately but, by tassel emergence (60 dap and onward), foliar disease severity was rated as the combined area affected by both diseases because it was impossible to tell how much of the leaf area was affected by one disease or the other, especially where infected areas overlapped. Therefore, spray applications were in response to the combined severity caused by both diseases, and the data analysis reflects that decision.

The first quantitative disease rating was on 25 July 2007. Disease assessments were continued until final disease severity measurements were made at 100, 91, and 89 dap in Bold, Jubilee, and GH 9597, respectively. In all instances, except for the first rating, severity was assessed, as described above for 2006, on each unfurled leaf of three plants per plot. For the first rating on 25 July 2007, disease incidence was assessed by scoring each of the plants in the middle two rows of each plot for the presence or absence of common rust pustules (no NCLB seen at this point in the main trial plots). Incidence data were converted to severities using an incidence $(I)-$ severity $(s)$ relationship (D. A. Shah, unpublished) developed from common rust data collected by the Dillard program from 1997 to 2001: $I=1-\exp (-104.91$ $\left.s^{\wedge} 0.7877\right)$.

The center two rows of all plots were harvested on 15 October 2007 (112 dap). Unlike in 2006, weight-per-ear determinations were made on unhusked ears in 2007. Therefore, yields were not directly comparable between years.

Data analysis. Within each hybrid, disease progression was not uniform across plots and some plots did not cross the thresholds assigned for spraying in the original experimental design. Therefore, it was illogical to do a factorial-type analysis of the data based on the experimental design. Instead, $t$ tests were used to compare final disease severities and yields of the different spray treatments with the corresponding metric from the unsprayed plots. The $t$ tests were done within each hybrid and year. Fungicide (Headline or Quadris) was dropped as a factor, because other statistical analyses (nonlinear mixed model curve fitting; data not shown) demonstrated that there were no differences between the two fungicides in terms of their effects on disease progress and yield for all three hybrids in both years. All $t$ tests were done with the TTEST procedure (SAS 9.2; SAS Institute, Cary, NC). The pooled (assuming equal variances for the groups) or the Satterthwaite (assuming the groups have unequal variances) version of the $t$ test was used, depending on the result of an equality of variances test which is part of the TTEST procedure. Although $t$ tests may seem overly simplistic, they gave the same qualitative results and interpretations as a more complex mixed model analysis comparing spray treatments (not shown) and are easier to understand; plus, they follow a general recommendation of analytical simplicity in ecological studies (12). Weight per ear data were also used to estimate the yield loss-severity relationship (29) via linear regression where such an analysis was possible.

\section{RESULTS}

2006 Trial in general. All 1\% threshold plots of the hybrid Bold were sprayed on 15 August 2006 (47 dap) and four of the $10 \%$ threshold plots were sprayed (two with Headline, two with Quadris) on 31 August 2006 (63 dap). None of the 20\% threshold plots were sprayed because foliar disease severities were either below threshold for the entire time that assessments were made or crossed $20 \%$ severity too late (about 79 dap) for sprays to have had time to sufficiently alter disease dynamics and associated yield loss (given harvest was at 90 dap). For Jubilee, only the $1 \%$ threshold plots were sprayed (all on 15 August 2006). None of the GH 9597 plots exceeded $1 \%$ foliar disease severity and, therefore, remained unsprayed. Plots scheduled for biweekly sprays were each sprayed four times. Final foliar disease severity in the unsprayed plots was low to moderate but hybrids were obviously different (Fig. 1A) in disease progress and in disease severity at the final assessment time (80 dap). Mean foliar disease severity in the unsprayed plots 80 dap was five times higher in Bold than in Jubilee and 60 times higher in Bold than in GH 9597 (Fig. 1A).

2007 Trial in general. A greater range of thresholds were met compared with the 2006 trial, because foliar disease severities
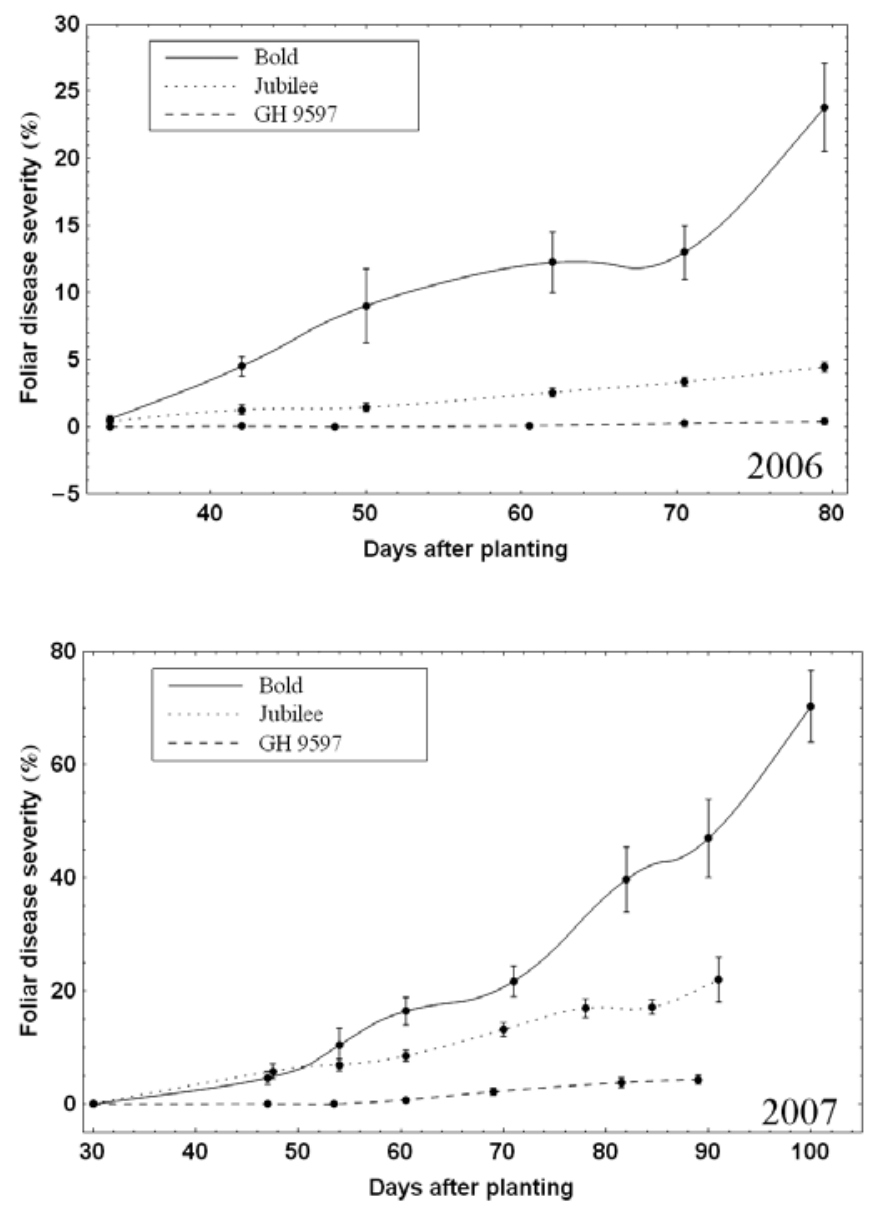

Fig. 1. Foliar disease progress in unsprayed plots of the hybrids Bold, Jubilee, and GH 9597 in 2006 and 2007. The vertical bars are standard errors. 
were generally higher in 2007. Control plots of each hybrid received two sprays of either Headline or Quadris on 23 July 2007 (28 dap) and 4 September 2007 (71 dap). All Bold plots crossed their respective thresholds (1, 10, and 20\%) and were sprayed accordingly. The $1 \%$ threshold plots were all sprayed on 13 August 2007 (49 dap), the 10\% threshold plots were all sprayed on 20 August 2007 (56 dap), and the $20 \%$ threshold plots were all sprayed on 7 September 2007 (74 dap). For Jubilee, all $1 \%$ threshold plots were sprayed on 13 August 2007 (49 dap), two of the 10\% threshold plots were sprayed on 28 August 2007 (64 dap) and the remaining four 10\% threshold plots were sprayed on 7 September 2007 (74 dap), and three 20\% threshold plots were sprayed on 13 September 2007 (80 dap). For GH 9597, five 1\% threshold plots were sprayed on 28 August 2007 (64 dap). None of the GH 9597 plots designated for spraying at 10 or $20 \%$ foliar disease severities crossed their respective thresholds and, therefore, remained unsprayed.
There were again (as in 2006) obvious differences in foliar disease progress among the hybrids (Fig. 1B). Mean final foliar disease severity in the unsprayed plots of Bold at 100 dap was three times higher than in Jubilee at 91 dap and 16 times higher than in $\mathrm{GH} 9597$ at 89 dap (Fig. 1B).

Disease severity: Bold 2006. Four biweekly sprays did not prevent foliar disease from increasing, though disease progress was slower and final severity was lower than that observed in unsprayed plots (Fig. 2). Spraying in response to the $1 \%$ threshold at 47 dap reduced foliar disease severity by an amount of $8.3 \%(95 \%$ confidence interval [CI]: 3.1 to $13.5 \%$ ) at 80 dap compared with unsprayed plots (Table 2). Spraying at 63 dap, when foliar disease severity exceeded $10 \%$, resulted in a reduction in foliar disease severity of $1.9 \%$ (95\% CI: -5.2 to $9.0 \%$ ) at 80 dap compared with unsprayed plots (Table 2; Fig. 2).

Disease severity: Jubilee 2006. The only plots that were sprayed (in addition to
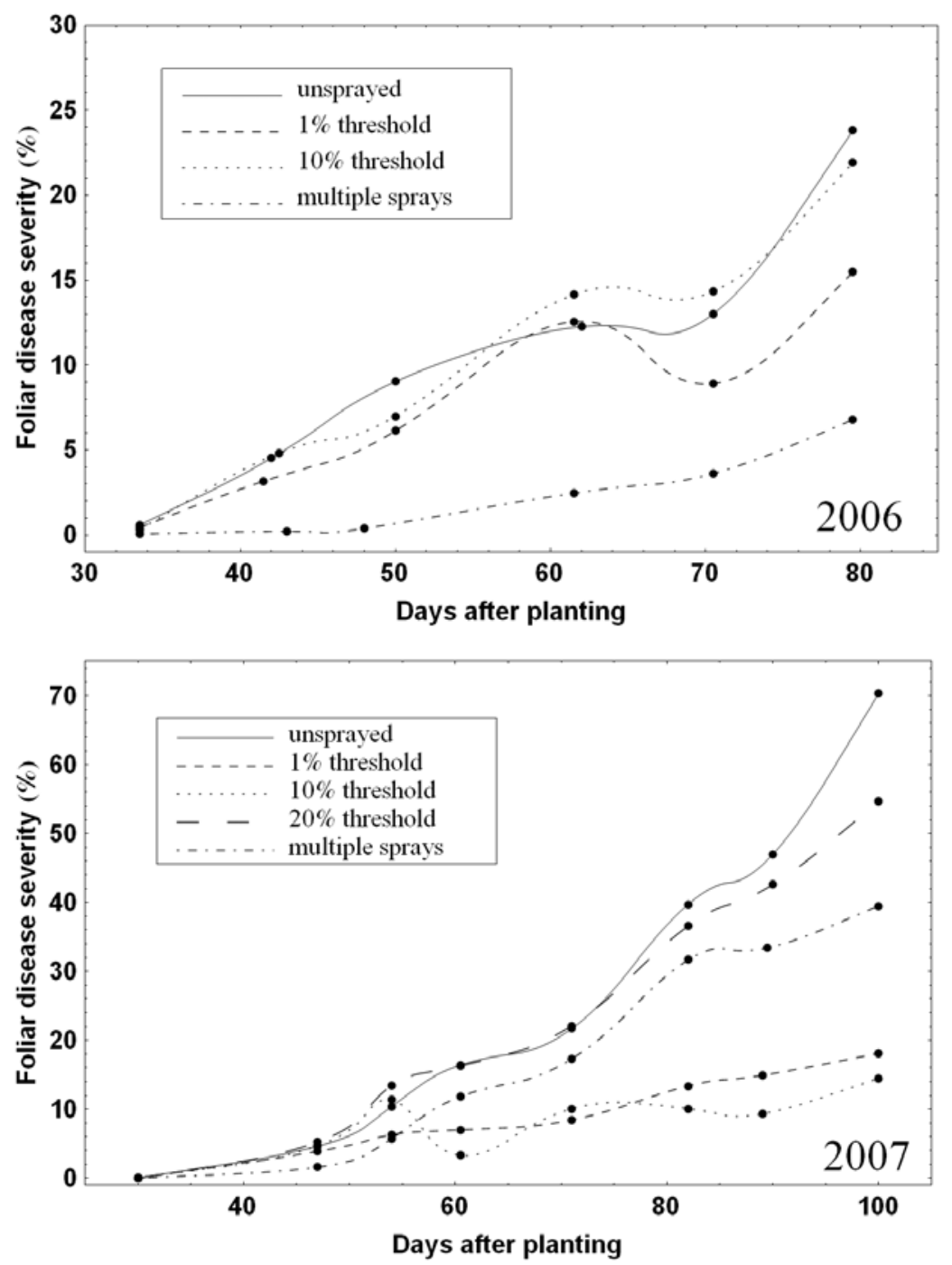

Fig. 2. Foliar disease progress curves for the hybrid Bold in 2006 and 2007 in response to single strobilurin sprays applied at targeted foliar disease thresholds. Plots receiving multiple sprays were treated biweekly (four sprays total) in 2006, and at 28 and 71 days after planting (i.e., two sprays) in 2007.

those sprayed biweekly) were ones designated for spraying at the $1 \%$ threshold (47 dap). Mean final foliar disease severity at 80 dap was less than $5 \%$ in all plots (Table 2). Foliar disease severity at 80 dap in plots sprayed at the $1 \%$ threshold was reduced by an amount of $0.5 \%$ (95\% CI: -0.3 to $1.3 \%$ ) compared with disease severity in unsprayed plots (Table 2).

Disease severity: GH 9597 2006. Foliar disease severities at 80 dap were less than $1 \%$ (Table 2). Therefore, none of the plots reached disease severities high enough to trigger fungicide applications in response to exceeded thresholds. Plots fell into two categories: unsprayed or treated biweekly Biweekly sprays did reduce disease severity but the mean realized reduction compared with unsprayed plots was $0.1 \%$ (95\% CI: -0.4 to $0.5 \%$; Table 2).

Disease severity: Bold 2007. Final foliar disease severity assessments were made at 100 dap (Table 2) and all sprays reduced foliar disease severity by this time compared with the unsprayed plots (Fig. 2 ). Compared with the unsprayed plots, spray treatments resulted in severity reductions amounting to $52.2 \%$ (95\% CI: 45.9 to $58.5 \%$ ), $55.8 \%$ (95\% CI: 48.5 to $63.2 \%$ ) $15.7 \%$ (95\% CI: 2.7 to $28.7 \%$ ), and $30.8 \%$ (95\% CI: 23.6 to $38.0 \%$ ) in plots sprayed at the 1, 10, and $20 \%$ foliar severity thresholds and those sprayed twice, respectively. The largest reductions in foliar disease severity compared with the unsprayed plots were achieved by spraying when disease severity exceeded either 1 or $10 \%$, which occurred 7 days apart. Foliar disease severity at 100 dap was 1.2 times higher in plots sprayed at the $1 \%$ foliar severity threshold compared with those sprayed at the $10 \%$ severity threshold but the difference was not significant $(P=0.1557)$.

Disease severity: Jubilee 2007. All spray treatments reduced foliar severity by 91 dap when compared with disease severity in unsprayed plots (Table 2). The most effective sprays were those applied when foliar disease severity exceeded either $1 \%$ (a reduction amounting to $7.5 \%[95 \% \mathrm{CI}$ : 2.1 to $13.0 \%$ ] by 91 dap) or $10 \%$ (a reduction amounting to $5.0 \%$ [95\% CI: -0.2 to $10.3 \%$ ] by 91 dap). In plots sprayed when foliar disease severity exceeded $20 \%$, the reduction amounted to $1.4 \%$ (95\% CI: -6.9 to $9.6 \%$ ) compared with unsprayed plots.

Disease severity: GH 9597 2007. As in 2006, final disease severities were low across all plots and did not exceed 6\% (Table 2). Sprays applied in response to foliar disease severity exceeding $1 \%$ were not effective in reducing disease severity by 89 dap when compared with the unsprayed plots (Table 2).

Rate of disease progress. Spline functions (Mathematica 7.0; Wolfram Research Inc., Champaign, IL) were used to plot the rate of foliar disease progress $(d y / d t)$ over time. The resulting curves are shown for unsprayed plots of the hybrid Bold in both 
2006 and 2007 (Fig. 3). The $d y / d t$ was initially higher in 2006 compared with 2007 but then slowed considerably between 40 and 60 dap. In the latter stages of the trial in 2006, dy/dt increased again but that increase came too late to affect the same levels of foliar disease severities seen in the 2007 trial. Notice that $d y / d t$ was generally $<2$. Inoculum availability (the borders of the 2007 trial were inoculated) and variability in conducive weather probably both influenced $d y / d t$, although the relative effects of each factor remain unknown.

Weather and disease increase. Temperatures were within the optimal ranges for both common rust and NCLB (data not shown). Cumulative rainfall from the first date on which quantitative disease assessments were made up to about 60 dap were similar between 2006 and 2007 (Fig. 3, inset). There was a period in 2007 , between 60 and 74 dap, in which there was no rain. At the end of the study, the 2006 trial had received $179 \mathrm{~mm}$ of rain between the first and last days of quantitative disease ratings, whereas the 2007 trial had received $101 \mathrm{~mm}$ of rain between those two defining points. Rainfall was not correlated with $d y / d t$ or with final foliar disease severities. Similarly, there was no apparent simple correlation between foliar disease increase and the cumulative number of hours in which relative humidity was $\geq 90 \%$ (RH90), or with leaf wetness duration (not shown). RH90 was higher in 2006 than in 2007 (Fig. 4, inset). The main plot in Figure 4 is a parametric plot of foliar disease severity and RH90 showing the state of these two variables at some particular dap, with dap increasing as one traces the curve from left to right. Foliar disease severity was higher in 2007 than in 2006 for comparable RH90 (Fig. 4).

Yields 2006. In Bold, husked ears were heavier in plots sprayed when foliar disease severity exceeded 1 or $10 \%$ compared with ears in unsprayed plots but the yields realized by these two spray treatments were not significantly greater than that from unsprayed plots (Table 3). Husked weight per ear data were used to estimate percent yield loss $(l)$ as a function of percent rust severity $(s)(29)$. The slope of the $l-s$ linear relationship was $0.885(95 \%$ CI: 0.764 to $\left.1.006 ; R^{2}=0.86\right)$, where $s$ ranged from 5.1 to $30.4 \%$.

In Jubilee also, yields in response to spraying (either at the $1 \%$ threshold or biweekly) were not significantly improved when compared with yields from the unsprayed plots (Table 3 ). The $l-s$ relationship ( $s$ ranging from 0.9 to $5.7 \%$ ) was poor $\left(R^{2}=0.06\right)$.

In GH 9597, biweekly sprays did not significantly increase weight per ear above that obtained in unsprayed plots (Table 3). Because disease severity was less than $2 \%$ in all plots, there was no reason to estimate $l-s$ relationships.
Yields 2007. In Bold, spraying in response to any one of the thresholds $(1,10$, or $20 \%$ ) increased weight per ear by 72 , 91 , and $20 \%$, respectively (Table 3 ). The largest yield increases were seen when single sprays were applied in response to the 1 and $10 \%$ thresholds. Unhusked weight per ear data were used to estimate percent yield loss $(l)$ as a function of percent foliar severity $(s)$, with final severities ranging from 8.2 to $78.9 \%$. The slope of the $l-s$ linear relationship was 0.721 (95\% CI: 0.669 to $0.774 ; R^{2}=0.96$ ).

In Jubilee, weight per ear was increased by 19 and $24 \%$ by spraying at the 1 and

Table 2. Observed final mean foliar disease severities

\begin{tabular}{|c|c|c|c|c|}
\hline \multirow[b]{2}{*}{ Year, hybrid } & \multirow[b]{2}{*}{ Treatment $^{\mathbf{a}}$} & \multicolumn{2}{|c|}{ Foliar disease severity $(\%)$} & \multirow[b]{2}{*}{$t$ test $P$ value $^{\mathrm{d}}$} \\
\hline & & Mean $^{b}$ & $95 \% \mathrm{CI}^{\mathrm{c}}$ & \\
\hline \multicolumn{5}{|l|}{2006} \\
\hline \multirow[t]{4}{*}{ Bold } & Unsprayed & 23.8 & $20.5,27.1$ & \\
\hline & $1 \%$ & 15.5 & $12.2,18.8$ & 0.0030 \\
\hline & $10 \%$ & 21.9 & $17.8,26.0$ & 0.5816 \\
\hline & Biweekly & 6.8 & $5.5,8.1$ & $<0.0001$ \\
\hline \multirow[t]{3}{*}{ Jubilee } & Unsprayed & 4.4 & $4.1,4.8$ & \\
\hline & $1 \%$ & 4.0 & $3.1,4.8$ & 0.2042 \\
\hline & Biweekly & 1.3 & $1.1,1.6$ & $<0.0001$ \\
\hline \multirow[t]{2}{*}{ GH 9597} & Unsprayed & 0.4 & $0.2,0.6$ & \\
\hline & Biweekly & 0.3 & $0,0.7$ & 0.7651 \\
\hline \multicolumn{5}{|l|}{2007} \\
\hline \multirow[t]{5}{*}{ Bold } & Unsprayed & 70.3 & $64.0,76.6$ & \\
\hline & $1 \%$ & 18.1 & $16.0,20.3$ & $<0.0001$ \\
\hline & $10 \%$ & 14.5 & $8.8,20.2$ & $<0.0001$ \\
\hline & $20 \%$ & 54.7 & $41.1,68.3$ & 0.0228 \\
\hline & $2 x$ & 39.5 & $34.1,44.9$ & $<0.0001$ \\
\hline \multirow[t]{5}{*}{ Jubilee } & Unsprayed & 22.0 & $18.1,26.0$ & $\ldots$ \\
\hline & $1 \%$ & 14.5 & $10.2,18.7$ & 0.0102 \\
\hline & $10 \%$ & 17.0 & $13.2,20.8$ & 0.0593 \\
\hline & $20 \%$ & 20.7 & $3.4,38.0$ & 0.7233 \\
\hline & $2 \times$ & 17.1 & $12.5,21.7$ & 0.0793 \\
\hline \multirow[t]{3}{*}{ GH 9597} & Unsprayed & 4.3 & $3.5,5.1$ & \\
\hline & $1 \%$ & 5.3 & $2.9,7.8$ & 0.2393 \\
\hline & $2 x$ & 3.7 & $2.3,5.0$ & 0.3837 \\
\hline
\end{tabular}

a Plots were unsprayed, or received a single spray if foliar disease severity crossed thresholds of 1,10 , or $20 \%$. Additional plots were sprayed biweekly in 2006 or twice $(2 x)$ in 2007.

${ }^{b}$ Final severity was assessed 80 days after planting (dap) in 2006. In 2007 final assessments were 100, 91, and 89 dap in Bold, Jubilee, and GH 9597, respectively.

${ }^{\mathrm{c}}$ For mean disease severity, $95 \%$ confidence interval (CI).

${ }^{\mathrm{d}} t$ tests compared disease severities for a given spray treatment against the unsprayed plots within a given year and hybrid.

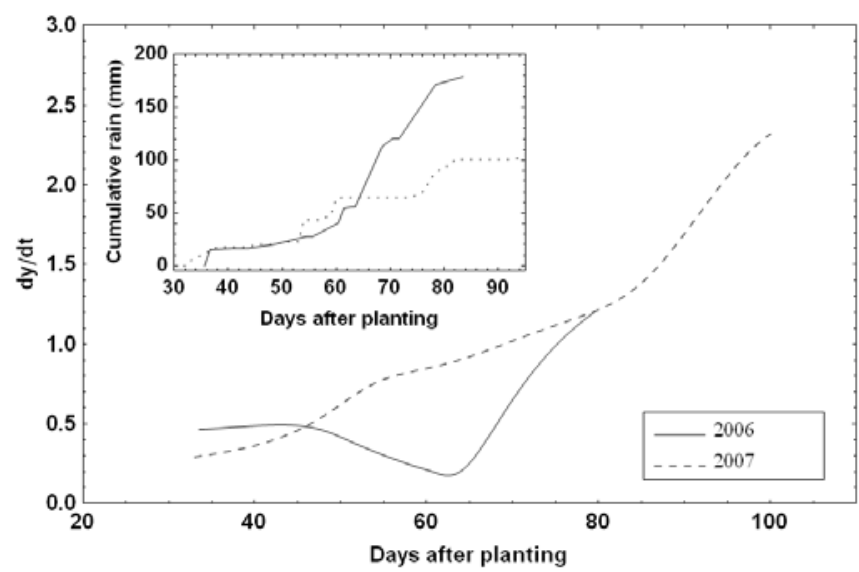

Fig. 3. Rate of change in foliar disease severity $(d y / d t)$ as a function of time ( $t=$ days after planting) in unsprayed plots of the hybrid Bold in 2006 and 2007. Inset: cumulative rain received at the trial site in 2006 and 2007 between the first and last dates of quantitative foliar disease intensity assessments. 
function of the various spray timings are used in Table 4. Although sprays may reduce foliar disease severity, a minimum increase of 8.5 to $10.2 \mathrm{~g}$ per ear is required for a single strobilurin spray to be considered cost effective in NY processing sweet corn. Therefore, none of the spray treatments in 2006 were cost effective. In 2007, spraying Bold at the 1 and $10 \%$ thresholds was cost effective, as well as spraying Jubilee at the $10 \%$ threshold. Note, however, that the strongest effects (largest margin of yield increase) were observed with Bold.

For common rust, cost effectiveness of a spray treatment can be determined indi- rectly if a minimum reduction of $15 \%$ in final foliar disease severity is achieved (29). Extending this criterion to the combined common rust and NCLB severities, none of the spray treatments in 2006 were cost effective and only the 1 and $10 \%$ spray treatments in Bold were cost effective in 2007.

\section{DISCUSSION}

Given the boundaries imposed upon foliar disease management in NY processing sweet corn, the current study demonstrated that a single strobilurin application against the two main foliar diseases (common rust and NCLB) can, indeed, be cost

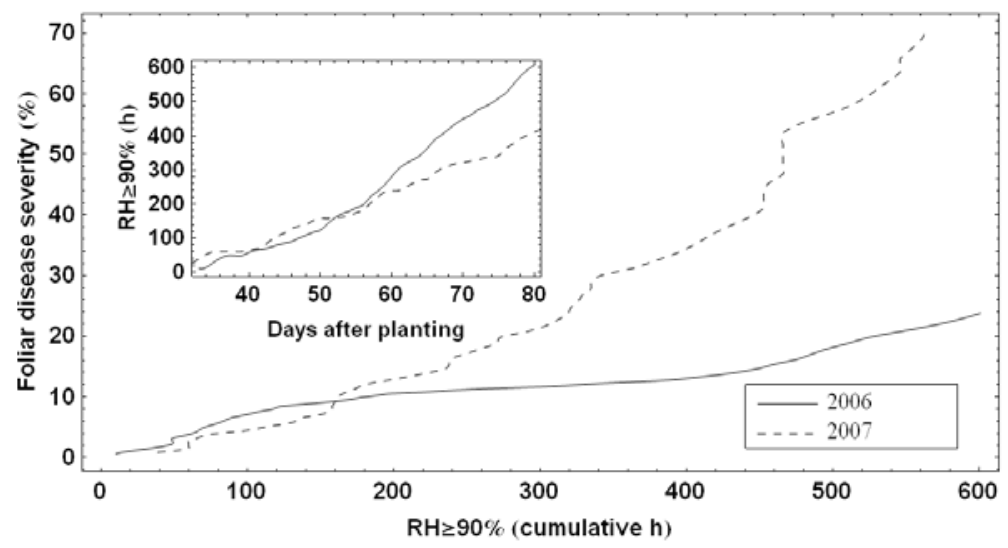

Fig. 4. Parametric plot showing the change in foliar disease severity in unsprayed plots of the hybrid Bold and cumulative number of hours in which relative humidity was $\geq 90 \%$. A parametric plot gives the $(x, y)$ coordinate of a point as a function of a third parameter; in this case, $t$ (= days after planting). Inset: cumulative number of hours in which relative humidity was $\geq 90 \%$ over time (days after planting), beginning from the date of the first quantitative disease intensity assessment.

Table 3. Yields of processing sweet corn hybrids when strobilurin fungicides were applied in response to foliar disease severities exceeding specified thresholds

\begin{tabular}{|c|c|c|c|c|}
\hline \multirow[b]{2}{*}{ Year, hybrid } & \multirow[b]{2}{*}{ Treatment $^{\mathrm{b}}$} & \multicolumn{2}{|c|}{ Weight per ear $(\mathrm{g})^{\mathrm{a}}$} & \multirow[b]{2}{*}{$t$ test $P$ value } \\
\hline & & Mean & $95 \% \mathrm{CI}$ & \\
\hline \multicolumn{5}{|l|}{2006} \\
\hline \multirow{4}{*}{ Bold } & Unsprayed & 170.3 & $158.6,182.0$ & \\
\hline & $1 \%$ & 187.1 & $174.0,200.2$ & 0.0568 \\
\hline & $10 \%$ & 186.2 & $168.1,204.4$ & 0.1592 \\
\hline & Biweekly & 200.2 & $185.3,215.0$ & 0.0013 \\
\hline \multirow[t]{3}{*}{ Jubilee } & Unsprayed & 188.2 & $176.5,199.9$ & \\
\hline & $1 \%$ & 191.8 & $178.7,204.9$ & 0.7179 \\
\hline & Biweekly & 195.9 & $182.5,209.3$ & 0.4352 \\
\hline \multirow[t]{2}{*}{ GH 9597} & Unsprayed & 226.0 & $219.3,232.6$ & \\
\hline & Biweekly & 238.4 & $221.3,255.5$ & 0.0708 \\
\hline \multicolumn{5}{|l|}{2007} \\
\hline \multirow[t]{5}{*}{ Bold } & Unsprayed & 188.6 & $176.8,200.5$ & \\
\hline & $1 \%$ & 325.1 & $296.0,354.2$ & $<0.0001$ \\
\hline & $10 \%$ & 359.6 & $330.5,388.7$ & $<0.0001$ \\
\hline & $20 \%$ & 226.0 & $194.9,257.1$ & 0.0155 \\
\hline & $2 \times$ & 281.0 & $256.2,305.8$ & $<0.0001$ \\
\hline \multirow[t]{5}{*}{ Jubilee } & Unsprayed & 201.6 & $182.6,220.7$ & $\ldots$ \\
\hline & $1 \%$ & 239.9 & $205.6,274.2$ & 0.0378 \\
\hline & $10 \%$ & 249.0 & $205.2,292.8$ & 0.0119 \\
\hline & $20 \%$ & 186.8 & $155.7,217.8$ & 0.5046 \\
\hline & $2 x$ & 257.5 & $214.0,301.1$ & 0.0038 \\
\hline \multirow[t]{3}{*}{ GH 9597} & Unsprayed & 361.1 & $343.7,378.4$ & $\ldots$ \\
\hline & $1 \%$ & 363.9 & $334.4,393.3$ & 0.8566 \\
\hline & $2 x$ & 372.7 & $342.0,403.5$ & 0.4567 \\
\hline
\end{tabular}

\footnotetext{
${ }^{a}$ Mean and $95 \%$ confidence interval (CI).

${ }^{\mathrm{b}}$ Plots were unsprayed, or received a single spray if foliar disease severity crossed thresholds of 1,10 , or $20 \%$. Additional plots were sprayed biweekly in 2006 or twice $(2 x)$ in 2007.

${ }^{c}$ Tests are within each year and hybrid, comparing weight per ear against the unsprayed plots.
}

effective but generally only in a susceptible hybrid prone to higher levels of disease development, and possibly in a moderately susceptible hybrid in some circumstances (Jubilee in 2007). In other words, the return on foliar fungicide investment was strongly dependent on hybrid resistance level (18). Although spraying reduced foliar disease severity in moderately susceptible and resistant hybrids, the yield improvements (if any) were not large enough to offset the costs associated with the spray program. Foliar disease control in sweet corn in NY is most worthwhile in susceptible hybrids, and is most likely to realize a cost-effective benefit if conditions allow disease increase to moderate or high levels before harvest, as seen in 2007.

The current study's results agree conceptually with another analysis showing that gray leaf spot control by fungicides in corn was cost effective largely in susceptible and moderately resistant hybrids, because the yield improvement in resistant hybrids was not enough to cover the costs of spraying (7). When only one fungicide application is possible, timing becomes a critical element of the spray program. As Munkvold (11) noted, a common recommendation for foliar disease control in corn is to apply the fungicide at first disease detection or disease onset. However, "onset" itself may be considered to have a subjective definition, highly dependent on scouting frequency (initiation of scouting and time interval between field visits) and intensity (number of assessed plants or leaves per plant). NY growers are skeptical about applications at first disease detection, because foliar disease presence is no guarantee of high disease intensities later on because of the unpredictability of future weather and its effects on disease progress. Their concern seems to be reinforced by the conditions experienced in 2006 and manifested in the disease progress curves evident in the field trial that year. In fact, initial rate of foliar disease progress in unsprayed Bold plots was higher in 2006 than in 2007 but disease progress slowed considerably after about 50 dap in 2006, and final disease severity was only about half that observed in 2007. No such midcrop disease slowdown was seen in 2007. From a strictly theoretical view, reducing the initial level of a polycyclic disease does not work relative to the length of the growing season unless the rate of disease progress is low (9). With a disease like common rust, even if the initial infections were eliminated, subsequent immigrant inoculum (i.e., from sources external to the field) could restart epidemics some time later. The data from the trials are consistent with theoretical arguments. Multiple fungicide applications in 2006, beginning at first disease detection, were unsuccessful in keeping foliar disease out of the plots that were treated, although the rate of disease progress was slowed relative to that in 
unsprayed plots. In 2007, the single fungicide application made at first disease detection at 28 dap did initially slow the rate of disease progress but it was apparent that foliar disease levels were beginning to approach those observed in the unsprayed plots as the season continued.

The striking difference in foliar disease progress and final foliar severities between the 2006 and 2007 trials is difficult to explain from the recorded weather variables. Plotted minimum and maximum daily temperatures showed that temperature conditions generally were within the optimal ranges for $P$. sorghi urediniospore germination and infection, and also for NCLB development $(4,34)$. A minimum leaf wetness duration (LWD) of $6 \mathrm{~h}$ favors common rust development (4) and extended LWD also favors NCLB (34). Contrary to observed disease progress, LWD was actually more favorable in 2006 than in 2007, assuming the Batavia weather station LWD data are extensible to the trial site. In $2006,83.3 \%$ of the days between the first and final foliar severity assessment dates had a LWD > 6 h whereas, in 2007, $53.5 \%$ of the days between the first and last quantitative foliar disease assessments had a LWD $>6 \mathrm{~h}$. High relative humidity also favors both diseases (34). The cumulative number of hours in which relative humidity was $\geq 90 \%$ was higher in 2006 from 60 dap onward when compared with the 2007 situation. Therefore, overall weather parameters would indicate that 2006 was more favorable for common rust and NCLB than 2007. Yet, disease severities were higher in 2007, and there was a marked period in 2006 in which the rate of disease progress approached zero. The more likely explanation for the discrepancy was a greater availability of local inocula in 2007 because of the presence of common rust and NCLB in the border rows.
Final disease severity is an endpoint of interest when assessing foliar blights in sweet corn, because of its utility in estimating the $l-s$ relationship, or damage function. The damage function itself can then be used to estimate the loss function or the reduction in financial return due to plant injury by pathogens (35). In an earlier article, Shah and Dillard (29) used a meta-analytic approach to estimate the $l-$ $s$ relationship for common rust in processing sweet corn. The meta-analysis returned an estimated slope of 0.470 (95\% CI: 0.236 to 0.704 ) for the linear $l-s$ function. In the present study, the estimated slopes of the $l-s$ function were 0.885 (95\% CI: 0.764 to 1.006) for Bold in 2006, 0.721 (95\% CI: 0.669 to 0.774 ) for Bold in 2007 , and 1.145 (95\% CI: 0.896 to 1.393) for Jubilee in 2007. These are consistent with the $l-s$ function slopes estimated by the meta-analysis. In the current study, the $l-$ $s$ slope estimates include the effects of NCLB, which may be reflected in the relatively higher slope estimate for the $l-s$ function in Jubilee in 2007.

In conclusion, single applications of strobilurin fungicides against foliar blights of processing sweet corn can be cost effective in NY. The application is most successful if made somewhere between 1 and $10 \%$ foliar disease severity on hybrids that are in the susceptible category. Foliar disease severity is difficult to estimate reliably (35), and incidence-severity relationships (10), if possible for foliar diseases of sweet corn, may be of utility in the practical determination of when the aforementioned thresholds are met.

\section{ACKNOWLEDGMENTS}

This research was funded by grants from the New York Farm Viability Institute (ARP 05 012) and the New York Vegetable Research Association/Council. We thank C. Crandall, J. Smith, and G. Jordan for maintaining the plots and applying the sprays.
LITERATURE CITED

1. Costello, S., Cockburn, M., Bronstein, J., Zhang, X., and Ritz, B. 2009. Parkinson's disease and residential exposure to maneb and paraquat from agricultural applications in the central valley of California. Am. J. Epidemiol. 169:919-926.

2. Dillard, H. R., and Seem, R. C. 1987. Use of incidence-severity relationships to determine the action threshold for common maize rust on sweet corn. Phytopathology 77:1700-1700.

3. Groth, J. V., Pataky, J. K., and Gingera, G. R. 1992. Virulence in eastern North American populations of Puccinia sorghi to $R p$ resistance genes in corn. Plant Dis. 76:1140-1144.

4. Headrick, J. M., and Pataky, J. K. 1986. Effects of night temperature and mist period on infection of sweet corn by Puccinia sorghi. Plant Dis. 70:950-953.

5. Hooker, A. L. 1985. Corn and sorghum rusts. Pages 208-236 in: The Cereal Rusts, Vol. 2. Academic Press, New York.

6. Jackson, T. A., Behn, J. L., and Miller, D. W. 2008. Evaluation of foliar fungicides on leaf diseases of corn in Nebraska, 2007. Plant Dis Manage. Rep. 2:FC058.

7. Jeschke, M., and Doerge, T. 2007. Management of foliar diseases in corn with fungicides In: Crop Insights. 17, no. 14. Pioneer Hi-Bred, Johnston, IA.

8. Levy, Y., and Pataky, J. K. 1992. Epidemiology of Northern leaf blight on sweet corn. Phytoparasitica 20:53-66.

9. Madden, L. V., Hughes, G., and van den Bosch, F. 2007. The Study of Plant Disease Epidemics. The American Phytopathological Society, St Paul, MN.

10. McRoberts, N., Hughes, G., and Madden, L. V. 2003. The theoretical basis and practical application of relationships between different disease intensity measurements in plants. Ann. Appl. Biol. 142:191-211.

11. Munkvold, G. 2006. Foliar fungicide use in corn. In: Crop Insights. 16, no.7. Pioneer HiBred, Johnston, IA.

12. Murtaugh, P. A. 2007. Simplicity and complexity in ecological data analysis. Ecology 88:56-62.

13. Nagarajan, S., and Singh, D. V. 1990. Longdistance dispersion of rust pathogens. Annu. Rev. Phytopathol. 28:139-153.

14. Pataky, J., Campaña, A., and Babadoost, M. 2002. Controlling common rust on sweet corn with strobilurin fungicides. Pages $87-90$ in: 2002 MWFPA Processing Crops Manual and

Table 4. Foliar severity disease reduction and yield responses to single strobilurin fungicide sprays applied when severity exceeded specified thresholds

\begin{tabular}{|c|c|c|c|c|c|c|c|c|}
\hline \multirow[b]{2}{*}{ Year, hybrid ${ }^{c}$} & \multirow[b]{2}{*}{$\bar{y}(\%)^{\mathbf{d}}$} & \multicolumn{3}{|c|}{ Disease reduction $(\%)^{\mathrm{a}}$} & \multicolumn{3}{|c|}{ Weight per ear increase $(g)^{b}$} & \multirow[b]{2}{*}{$z^{\mathrm{e}}$} \\
\hline & & $1 \%$ & $10 \%$ & $20 \%$ & $1 \%$ & $10 \%$ & $20 \%$ & \\
\hline \multicolumn{9}{|l|}{2006} \\
\hline Bold & 23.8 & $3.1,13.5$ & $-5.2,9.0$ & $\ldots$ & $-2.0,35.7$ & $-9.5,41.5$ & $\ldots$ & 0.885 \\
\hline Jubilee & 4.4 & $-0.3,1.3$ & $\ldots$ & $\cdots$ & $-17.6,24.7$ & $\ldots$ & $\cdots$ & $\ldots$ \\
\hline GH 9597 & 0.4 & $\ldots$ & $\ldots$ & $\ldots$ & $\ldots$ & $\ldots$ & $\ldots$ & $\ldots$ \\
\hline \multicolumn{9}{|l|}{2007} \\
\hline Bold & 70.3 & $45.9,58.5$ & $48.5,63.2$ & $2.7,28.7$ & $109.2,163.7$ & $143.7,198.2$ & $8.5,66.2$ & 0.721 \\
\hline Jubilee & 22.0 & $2.1,13.0$ & $-0.2,10.3$ & $-6.9,9.6$ & $6.3,70.2$ & $10.5,84.2$ & $-48.8,19.0$ & 1.145 \\
\hline GH 9597 & 4.3 & $-0.7,2.8$ & $\ldots$ & $\ldots$ & $-29.9,35.5$ & $\ldots$ & $\ldots$ & 0.197 \\
\hline
\end{tabular}

${ }^{a}$ The 95\% confidence interval (CI) for the reduction in final foliar disease severity compared with unsprayed controls when a single strobilurin spray was applied if foliar disease severity crossed thresholds of 1,10 , or $20 \%$. Missing values indicate where disease severity did not cross the required threshold, or did so too late in the season for spray application. CIs which include 0 indicate no significant reduction of final foliar disease by sprays.

${ }^{b}$ The $95 \%$ CI for the increase in weight per ear compared with unsprayed controls when a single strobilurin spray was applied if foliar disease severity crossed thresholds of 1,10 , or $20 \%$. Missing values indicate where disease severity did not cross the required threshold, or did so too late (within 20 days of anticipated harvest) for a spray application. A spray treatment would have been considered cost effective if the weight per ear increase exceeded 8.5 to $10.2 \mathrm{~g}$.

${ }^{c}$ In 2006, final disease severity was assessed in all three hybrids 80 days after planting (dap); Bold, Jubilee, and GH 9597 plots were harvested at 90, 90 , and 103 dap, respectively. In 2007, final disease severity assessments were made at 100, 91, and 89 dap in Bold, Jubilee, and GH 9597, respectively; all three hybrids were harvested at 112 dap.

d $\bar{y}=$ Mean observed foliar disease severity in unsprayed plots at the final assessment date.

e Slope of the relationship between yield loss (weight per ear) and final foliar disease severity. 
Proceedings. Midwest Food Processors Associations, Madison, WI.

15. Pataky, J. K. 1992. Relationships between yield of sweet corn and northern leaf blight caused by Exserohilum turcicum. Phytopathology 82:370-375.

16. Pataky, J. K. 1995. Successful use of resistance to control diseases of sweet corn. Plant Dis. 79:1256-1258.

17. Pataky, J. K., and Campaña, M. A. 2007. Reduction in common rust severity conferred by the $R p 1 D$ gene in sweet corn hybrids infected by mixtures of Rp1D-virulent and avirulent Puccinia sorghi. Plant Dis. 91:1484-1488.

18. Pataky, J. K., and Eastburn, D. M. 1993. Comparing partial resistance to Puccinia sorghi and applications of fungicides for controlling common rust on sweet corn. Phytopathology 83:1046-1051.

19. Pataky, J. K., and Eastburn, D. M. 1993. Using hybrid disease nurseries and yield loss studies to evaluate levels of resistance in sweet corn. Plant Dis. 77:760-765.

20. Pataky, J. K., Raid, R. N., du Toit, L. J., and Schueneman, T. J. 1998. Disease severity and yield of sweet corn hybrids with resistance to northern leaf blight. Plant Dis. 82:57-63.

21. Peterson, R. F., Campbell, A. B., and Hannah,
A. E. 1948. A diagrammatic scale for estimating rust intensity on leaves and stems of cereals. Can. J. Res. Sect. C 26:496-500.

22. Raid, R. N. 2006. Efficacy of fungicides for control of common rust on sweet corn, 2005. Fungic. Nematicide Tests 61:V048.

23. Raid, R. N. 2006. Efficacy of strobilurin fungicides, alone and in pre-mixtures, for control of common rust on sweet corn, 2005. Fungic. Nematicide Tests 61:V049.

24. Raid, R. N. 2007. Efficacy of fungicides for control of common rust on sweet corn, Spring 2006. Plant Dis. Manage. Rep. 1:V092.

25. Rodriguez-Brljevich, C., Shriver, J. M., and Robertson, A. E. 2008. Effectiveness of foliar fungicides on hybrid corn in Nashua, Iowa 2007. Plant Dis. Manage. Rep. 2:FC097.

26. Sanders, F. H., Jr., and Langston, D. B., Jr. 2008. Evaluation of fungicides for control of common rust of sweet corn on a resistant and a susceptible cultivar, 2007. Plant Dis. Manage. Rep. 2:V175.

27. Shah, D. A., and Dillard, H. R. 2004. Possible sources of Puccinia sorghi inoculum initiating rust epidemics on sweet corn in western New York, 2002. (Abstr.) Phytopathology 94:S95.

28. Shah, D. A., and Dillard, H. R. 2005. Identify- ing possible initial inoculum sources for common rust on sweet corn using back trajectory analyses. (Abstr.) Phytopathology 95:S172.

29. Shah, D. A., and Dillard, H. R. 2006. Yield loss in sweet corn caused by Puccinia sorghi: a meta-analysis. Plant Dis. 90:1413-1418.

30. Shaner, G., and Buechley, G. 2006. Control of leaf diseases of seed corn in Indiana with foliar fungicides, 2005. Fungic. Nematicide Tests 61:FC037.

31. Shaner, G., and Buechley, G. 2008. Control of leaf diseases of seed corn in Indiana with foliar fungicides, 2007. Plant Dis. Manage. Rep. 2:FC036.

32. Shaner, G., Buechley, G., and Johnson, R. 2007. Control of leaf diseases of seed corn in Indiana with foliar fungicides, 2006. Plant Dis. Manage. Rep. 1:CF003.

33. Trevisan, M., Di Guardo, A., and Balderacchi, M. 2009. An environmental indicator to drive sustainable pest management practices. Environ. Modell. Softw. 24:994-1002.

34. White, D. G., ed. 1999. Compendium of Corn Diseases. American Phytopathological Society Press, St. Paul, MN.

35. Zadoks, J. C. 1985. On the conceptual basis of crop loss assessment: the threshold theory. Annu. Rev. Phytopathol. 23:455-473. 